\title{
An evaluation of the relevance and
}

appropriateness of post-basic nursing programmes offered by the University of Zululand in meeting graduates'needs

\author{
BA Kubheka, D.Phil., Department of Nursing Science, University of Zululand \\ PN Nzimande, D.litt et Phil, Department Of Nursing Science, University Of Zululand
}

\section{Abstract}

This article aims at evaluating the relevance and appropriateness of post-basic nursing programmes of the University of Zululand Nursing Science Department in meeting the educational needs of the graduates in the Province.

An explanatory descriptive survey was conducted in the hospitals,clinics, nursing colleges, nursing schools and the University of Zululand where the nursing graduates worked. Two sets of interview schedules were designed, one for nursing graduates and one for their supervisors. These interview schedules consisted of open and closed-ended questions. The total number of graduates was 75 and 29 supervisors. The respondents were purposively and conveniently selected according to the availability of post-basic nursing graduates in each health and nursing education institution.

The study revealed that post-basic nursing programmes of the University of Zululand catered for the changing learning needs of the graduates. This was due to the comprehensiveness of the programmes and their focus on community based and primary based health care from 1996.

Based on the findings of the research it was recommended that a continuous evaluation of the post-basic nursing programmes is done, in order to check if they still meet the changing learning needs of the graduates.

It was further recommended that the Nursing Science Department should develop more advanced clinical nursing programmes in order to cater for the recent learning needs of the graduates.

\section{Introduction}

Each nursing educational institution provide its own nursing educational programmes that differ from those of other institutions. However, they do have one thing in common, and that is to provide educational programmes that will cater for the needs of the students. The programmes should be evaluated from time to time to see if they are still appropriate and are relevant to these needs. Pietzak, Ramlar, Ford, Renner and Guilbert (1990: 220) indicate that programme evaluation is done to assess the value or to make judgements on the worth of the programmes. This was the reason why the post-basic nursing programmes of the University of Zululand's Nursing Science Department were evaluated to determine whether they are appropriate and relevant to the needs of the graduates in KwaZulu-Natal province.

Mellish and Brink (2001: 316 - 317) stated that evaluation of programmes should be done jointly by the principal, the staff and students considering the community needs and that the following questions should be asked:

- Are nurses registered as a result of the programme, able to act effectively?

- Do the programmes meet the needs of the graduates?

Billing and Halstead (1998: 198) agree with above authors by saying that every programme should demonstrate its relevance and appropriateness to the learning needs of students. Furthermore, Rosie and Freeman (1991: 56) warn that if a programme do not cater for the above needs, it 


\section{Background of the study}

The Nursing Science Department of the University of Zululand commenced with the introduction of post-basic nursing programmes in 1981 . There was no evidence that these post-basic nursing programmes had been evaluated since that date. As a result this study was conducted to evaluate post-basic nursing programmes offered from 1981 - 1998. The subjects that were evaluated are nursing education, nursing management and community health nursing science, all at diploma, degree, honours, masters and doctoral levels.

When the Nursing Science Department was established in 1981, the comprehensive health service approach was followed in South Africa as a whole, including KwaZulu-Natal. This approach emphasised integrating the services and focusing them on the community. During this time education was based on the old system that did not serve the country well and was out of step with world trends. It catered for passive learners driven by examinations, learning in parrot fashion and completely centred on the teacher (Department of Education, 1997:5).

In 1996 the post-basic nursing programme's philosophy was revised to cater for the requirements of the Government of National Unity that was introduced in 1994, and the changed needs of the communities. The revised philosophy became relevant to the recent changes in the curriculum, the health needs of the country and the learning needs of students. The philosophy was formulated based on the new system of education that evolved around the concept of transformational outcomes-based education (OBE). Under this system learners become active participants in school and throughout life, learners are at the centre of learning and teachers act as facilitators. Learners are thus responsible for their own learning and progress (Department of Education, 1997:6). The revised programmes placed more emphasis on comprehensive primary health care delivery and nursing education, which was transformed and restructured. More emphasis was also placed on research, caring and the learning process, which is based on inquiry, discovery, creativity and critical thinking (Nzimande, 1990:8). Billing and Halstead (1998: 198) comment that traditional methods of teaching need to be abandoned if we are to produce the critical thinkers that are needed in the clinical areas. All the above attributes of the philosophy will enable the nursing graduates to function within a transforming health care system and society.

For the post-basic nursing programmes to be relevant and appropriate to the educational needs of graduates the following goals and objectives were formulated for the nursing science department by the head of department and staff members.

- To prepare already qualified nurses to function within and to give direction to emerging nursing roles as patterns of a health care delivery change.

- To develop students so that they can assume lead- ership responsibilities within their profession with transforming health systems and within the larger society.

- To participate as agents of change in the social and political actions for the empowerment of health care and its delivery.

- To prepare advanced nursing practice specialists to be competent to meet current and future challenges in the restructuring and transforming health care systems.

- To apply leadership knowledge and skills in implementing the role of advanced nursing practice specialists and developing strategies that advance health care and nursing education.

- To develop collaborative relationships with professions in other disciplines to assess and meet the educational needs of the graduates (Nzimande, 199(): 7-10).

In this study the relevance and appropriateness of the nursing programmes in catering for the educational needs of the students in KwaZulu-Natal province, was evaluated by assessing the performances of the graduates in their work places. The supervisors of the graduates were also included and were given the opportunity to comment on the performance of the graduates in different health services and educational institutions. The good performances of the graduates would confirm their relevance and appropriateness of the nursing programmes. Rossie and Freeman (1991: 58) comment that nursing programmes that have failed to meet the community concerns and quality of services provided by the graduates, require some modification of objectives, outcomes criteria and preparation of the graduates.

For this reason it was deemed imperative that the impact of the post-basic nursing programmes of the University of Zululand Nursing Science Department be evaluated to see if they catered for the educational needs of the graduates.

\section{Objectives of the study}

The objectives of this study were:

- To ascertain the relevance and appropriateness of the post-basic nursing programmes of the University of Zululand in catering for the educational needs of the nursing students.

- To identify the contributions made by nursing graduates in their work places.

- To identify the developmental needs of the nursing graduates.

- To make suggestions for future preparation of the nursing graduates.

\section{Statement of the problem}

The financial constraints facing tertiary institutions today as well as the need for relevance, productivity and appropriate nursing programmes, demands continuous evalua- 
tion of programmes that are offered. This should be done in order to assess the relevance of the curriculum to meet the educational needs of the graduates.

Each tertiary educational institution should justify its existence by among other things providing cost-effective nursing education programmes. If any nursing programme is not relevant to the needs of the students, it will serve no purpose and therefore would require some changes and improvements.

\section{Research questions}

1. Are post-basic nursing programmes of the University of Zululand Nursing Department relevant to the educational needs of students of the KwaZulu-Natal province?

2. What contributions have these graduates made in their working areas?

\section{Definition of terms}

\section{Programme}

Programme is defined in this study as a series of planned education activities a student is to undertake with the assistance of the teacher.

\section{Evaluation}

Evaluation is defined as the collection and interpretation through systematic and formal means of relevant information that serves as basis for rational judgements in decision-making (Billing \& Halstead, 1998: 423).

\section{Post-basic nursing programmes}

In the context of this study post-basic nursing is used to refer to all nursing programmes that are offered after a basic nursing programme, where a professional nurse obtains additional qualifications which are approved and registered by the South African Nursing Council.

\section{Research method}

\section{Research Design}

An exploratory and descriptive survey was used to collect data. This was used to evaluate the impact of post-basic nursing programmes offered by the University of Zululand and the relevance and appropriateness of these programmes in catering for the educational needs of the graduates. Data collection took place in the province of KwaZuluNatal, regions B, D, E, F and $H$ health services and educational institutions.

\section{Sample and Sampling}

A purposive, convenience and systematic random sampling of 75 post-basic graduates and 29 supervisors was done.

\section{Selection of the post-basic nursing graduates}

Selection of the graduates was done according to their avail- ability in the hospitals, clinics, nursing colleges, nursing schools and the University of Zululand where they were employed. This was done after doing a situational analysis in the above institutions. In the institutions where the nursing graduates were less than 10 , they were all purposively and conveniently selected. In the institutions where nursing graduates were more than 10 , a systematic random sampling procedure was done. Every tenth nursing graduate was selected until the 75 graduates were selected.

\section{Selection of supervisors}

The immediate supervisors of the graduates were purposively selected to comment about performances and contributions made by the nursing graduates in their work places.

\section{Ethical consideration}

Permission was obtained from the Department of Health, superintendents of individual hospitals, clinics, and principals of nursing colleges, principal of the nursing schools and heads of the department of the University of Zululand. Informed consent was obtained from nursing graduates and their supervisors. They were requested to partake voluntarily and were assured of confidentiality.

\section{The instrument}

The instrument consisted of both close-ended and open ended and questions to allow respondents an opportunity to express their views freely. The design was guided by the literature review and objectives of the study. Two sets of interview schedules were designed, one for nursing graduates of the University of Zululand and the other for their supervisors in the working areas. Both interview schedules comprised of sections.

Section A comprised of demographic data with 2 questions on gender of respondents and distribution and area of employment.

Section B comprised of one question on the area of employment.

Section C comprised of educational qualifications with one question where graduates had to mention the educational qualification they obtained from the University of Zululand.

Section D comprised of 3 questions on the relevance and appropriateness of post-basic nursing programmes to cater for work needs of the graduates.

The questions are:

- ability of graduates to correlate theory and practice

- $\quad$ coping with recent advances

- ability of post-basic nursing programmes to cater for work needs of graduates

Section E comprised of 4 questions on contributions made by nursing graduates in their working areas.

The questions are:

- contributions in nursing management 
Section G comprised of I questions of developmental needs of the graduates.

Section $\mathbf{H}$ comprised of 3 questions on suggestions for future preparations.

The questions are:

- $\quad$ suggestions on nursing management

- $\quad$ suggestions on nursing education

- suggestions in community health nursing and primary health care

\section{Table 1 - Gender of Respondents}

\section{Face and content validity of the instrument}

Experts, senior lecturers and deputy directors of different educational institutions and health services assessed face and content validity of the instrument. They all agreed that the instrument was

\begin{tabular}{|l|l|l|l|l|}
\hline Category & \multicolumn{2}{|l|}{ Females } & \multicolumn{2}{l|}{ Males } \\
\hline & frequency & Percentage & frequency & Percentage \\
\hline Graduates $\mathrm{N}=75$ & 73 & 97.40 & 2 & 2.60 \\
\hline Supervisors $\mathrm{N}=75$ & 28 & 96.40 & 1 & 3.40 \\
\hline
\end{tabular}
suitable and adequate to measure what it was intended to measure. The instrument was also pretested on 10 professional nurses and 5 chief professional nurses who did not form part of the main study. This was done to check the suitability of the instrument. Minor grammatical changes were made before administration of the instrument. Each interview took about 15 - 20 minutes for each respondent.

\section{Data collection}

The data was collected by the researcher and a well trained assistant researcher who was also an experiences researcher from each respondent during a face to face interviews. All the respondents that were on duty in each institution were interviewed until a sample of 75 graduates and 29 supervisors was interviewed.

\section{Data analysis}

Data was analysed by a statistician. Responses from open ended questions were classified coded and sub-coded for purposes of quantitative analysis by a statistician and was presented in the form of tables and graphs.

\section{Research}

\section{findings and discussions}

\section{Demographic data}

\section{Gender}

This variable was considered important because some specialities need male nurses in the nursing profession, such as orthopaedic nursing, psychiatric nursing, mining industries and others. If the males are less in the above specialities the health needs of the country cannot be properly met. The study revealed that there were more females (73) $97.40 \%$ than males (2) $2.60 \%$. This picture was the same for supervisors of the graduates, that is (28) $96.60 \%$ females and (1) $3.40 \%$ males. The nursing profession as a whole thus need to recruit and attract more males to change the picture of being dominated by females in order that the health needs of the country are properly catered for see (table 1).

\section{Age distribution}

The results in table 2 shows that the majority (31) $41.30 \%$ fell in the age group $31-40$ years, (27) $36 \%$ within $41-50$ years, (14) $18.70 \%$ within the age group of $51-61$ and (3) $4 \%$ into the age group of 21 - 30 years. This was an indication that the nursing graduates were mature enough to work in the health services and educational institution. The majority of the supervisors fell in the category of 51-61 years (14) $48.27 \%$, followed by (9) $31.03 \%$ in the category 41 - 50 years, $31-40$ years were (5) $17.30 \%$ and only (1) $3.40 \%$ were in the category $21-30$ years. This indicates that the supervisors were experienced enough to evaluate the nursing graduates.

\section{Area of employment}

The results indicates that the nursing graduates of the University of Zululand and their supervisors were employed equally in rural, urban and suburban areas namely, $33.30 \%$ in each area. The reason might be that the University has

\section{Table 2 - Age distribution}

\begin{tabular}{|l|l|l|l|l|}
\hline \multicolumn{2}{|l|}{ Graduates N=75 } & \multicolumn{3}{l|}{ Supervisors N=29 } \\
\hline Age distribution & Numbers & Percentage & Number & Percentage \\
\hline $21-30$ & 3 & 4 & 1 & 3.40 \\
\hline $31-40$ & 31 & 41.30 & 5 & 17.30 \\
\hline $41-50$ & 27 & 36 & 9 & 31.03 \\
\hline $51-61$ & 14 & 18.70 & 14 & 48.27 \\
\hline Above & 75 & 100 & 29 & 100 \\
\hline
\end{tabular}


two campuses, one at Empangeni that is rural, suburban and urban in nature and the Durban-Umlazi Campus, which has the same characteristics. This meant that nursing graduates were catered for equally for their educational needs in rural, suburban and urban communities.

\section{Educational qualifications}

Most of the graduates (30) 40\%, had B.Cur E at A (baccalaureate degree in nursing) with majors in nursing management, nursing education and community health nursing science. The others (29) $38.70 \%$ had diplomas in the above-mentioned specialities. Very few nursing graduates had post-graduate qualifications at honours, masters and doctoral levels. Eleven $14.70 \%$ had an honours degree, (4) $5.30 \%$ a masters degree and only (1) $1.30 \%$ had a doctoral degree. In the light of these findings it could be argued that nursing graduates were catered well for their educational needs.

\section{Relevance and}

\section{appropriateness of post- basic programmes to cater for the educational needs of nursing graduates}

It became necessary to ask the nursing graduates whether the post-basic nursing programmes they undertook catered for their educational needs.

\section{Ability of post-basic programmes to cater for work needs of graduates}

Table 3 indicates that post-basic nursing programmes catered for graduates' work needs (69) $92.00 \%$ as compared to (3) $4.00 \%$ who responded negatively and another (3) $4.00 \%$ who did not respond. It is clear from these findings that nursing programmes were relevant and catered for the educational needs of the graduates. Billing and Halstead (1998: 198) see programme evaluation as aiming at assessing the effect of the programmes in helping graduates to acquire knowledge and skills necessary to function effectively.

\section{Ability of the graduates to correlate theory and practice}

This question was asked to ascertain if graduates were able to practice what was taught at University. The majority of the graduates (71) $94.70 \%$ were able to practice what was taught at University. In other words, they were able to correlate theory and practice. Only (4) $5.30 \%$ were unable to practice what was taught. The ability to practice is a sign that post-basic nursing programmes were relevant to the
Table 3 - Ability of post-basic programmes to cater for work needs of graduates

\begin{tabular}{|l|l|l|}
\hline Response & Graduates $\mathbf{N}=\mathbf{7 5}$ & Percentage \\
\hline Yes & 69 & $92.00 \%$ \\
\hline No & 03 & $4.00 \%$ \\
\hline No Response & 03 & $4.00 \%$ \\
\hline Total & 75 & $100 \%$ \\
\hline
\end{tabular}

needs of the graduates and the needs of the country. It also meant that these programmes improved knowledge and skills of the graduates.

Bitzer( 1994:42) and Mellish and Brink (2001: 316) suggest that nursing programmes should be evaluated in order to find out if the graduates are able to act effectively in their clinical areas by correlating knowledge gained into practice.

\section{Coping with recent advances}

Graduates were asked if they were able to cope with recent advances in the health services. This was done for the purpose of assessing the relevance of the post-basic programmes of the University of Zululand Nursing Science Department to the needs of the students and the needs of the country they served. The majority (72) $96.00 \%$ were coping with recent advances as compared to (3) $4.00 \%$ who responded negatively.

To confirm whether the graduates were coping with recent advances, they were asked about the relevance of their education and training to outcome-based education and primary health care, which were some of the recently implemented changes in the curriculum. Graduates (39) $52.00 \%$ felt that their education and training were relevant to primary health care and (36) $48.00 \%$ to outcome-based education. These two educational strategies are relevant to all programmes, that is nursing education, nursing management and community health nursing. Zuma (1996: 15), the previous minister of health in the Government of National Unity mentioned that training programmes of health professionals should be reviewed to include primary health care.

There are many other changes taking place in the country that require continuous updating of knowledge and skills of nursing personnel in order to cope appropriately. Mellish and Brink (2001: 316) state that nurse educators should evaluate the programmes they offer to assess whether they meet the health needs of the country and needs of the graduates. This points to the relevance of the nursing programmes at the University of Zululand to the needs of the graduates in order to cater for the changing needs of the citizen of KwaZulu-Natal Province.

Appropriateness of 


\section{graduates training to face the future needs of the health services}

The supervisors of the graduates were asked if the training of graduates was appropriate for them to face the future needs of the services. The majority of supervisors (28) $96.60 \%$ as compared to (1) $3.40 \%$ confirmed that the graduates from post-basic nursing programmes of the University of Zululand were appropriately trained to face the transformational needs of South African health service needs. The reason for this is that these graduates had been prepared in the new curriculum strategies as well as new transformational leadership skills. This confirms the view of Gumbi (1996: 35), the national human resource planner and chief Director of National Health, during that time in that "one of the contributions of human resources development will be education of health personnel who are innovative, with good leadership and supervisory skills and good decision makers who will effectively address the countries needs".

\section{Competence in work performance}

Graduates were asked if they were feeling competent in their work performance. Competence of the graduates will always reveal the appropriateness of their knowledge and skills in catering for the changing health needs of the country. (20) $93.30 \%$ graduates felt competent in their work performance. Only (5) 6.70\% were not competent. This means that the graduates were competent enough to cater for their work needs. Ferguson and Calder ( 1993: 31 ) argue that competence should not involve only psychomotor performance, but also knowledge, values, critical thought, clinical judgement and other complex skills.

\section{Significant contributions made by the nursing graduates in their working}

\section{areas}

To confirm the relevance of the post-basic nursing programmes to their educational needs, graduates themselves were asked to identify some contributions that they had made in their work places. The supervisors also had to comment about the specific contributions made by nursing graduates in their work places. Supervisors stated that nursing graduates made various contributions in the institutions. The graduates mentioned various contributions that they made in each department. The contributions ranged from nursing administration, working in the clinical areas, nursing education and primary health or clinics.

\section{Contributions in nursing administration}

Thirty one $41.30 \%$ graduates stated that they made contributions in nursing administration on the following:
(15) $20.0 \%$ graduates formulated policies, rules and regulations.

- (5) $6.70 \%$ improved administrative skills for nurses.

- (5) $6.70 \%$ conducted nursing audits, patients' quality assurance and quality improvements.

- (3) $4.00 \%$ became Involved in conflict management of a multidisciplinary team.

- $\quad$ Another (3) $4.00 \%$ contributed by formulating and implementing orientation programmes for new staff members.

According to Nzimande (1984: 45) nurse managers occupying high positions should be involved in planning of health services and policy making in order to utilize their knowledge effectively.

\section{Comments by supervisors on contributions made by graduates}

Nine $31.00 \%$ supervisors of nursing graduates agreed that graduates contributed significantly in the following:

- (2) $6.80 \%$ supervisors stated that (5) $6.70 \%$ graduates contributed by formulating team leaders in the implementation of the nursing process.

- (2) $6.8 \%$ supervisors stated that (6) $8.00 \%$ graduates contributed by Improving administrative procedures and record keeping of patients.

- (1) $3.40 \%$ supervisor said (5) $6.70 \%$ graduates helped with accreditation.

- (1) $3.40 \%$ supervisor stated that (3) $4.00 \%$ graduates were involved in budgeting of the institution.

- (2) $6.80 \%$ supervisors mentioned that (5) $6.70 \%$ graduates assisted with occupational health safety and infection control.

- $\quad$ The last supervisor (1) $3.40 \%$ mentioned that (2)

$2.70 \%$ graduates conducted meetings to solve problems for staff members on their own. According to supervisors (26) $34.60 \%$ graduates contributed tremendously in nursing management, which is a sign that graduates were well prepared by the University of Zululand

\section{Contributions in the clinical areas}

Contributions in the clinical areas were made mostly in the improvement of patient care as indicated by (6) $6.70 \%$ and (1) $1.30 \%$ graduates by implementing of the nursing process. Improvements in patient care are one of the main objectives of health services, which is an indication that nursing graduates were properly prepared to cater for their educational needs. Huber (1996: 491) states that quality measures are needed to measure professional actions in caring for the patients.

Ten $34.48 \%$ supervisors of the nursing graduates identified the same contributions made by nursing graduates as those mentioned above, Over and above (7) $9.30 \%$ supervisors stated that (2) $6.80 \%$ graduates contributed by supervising clinical teaching for bridging students which is 
very difficult to do especially if there are staff shortages.

\section{Contributions made in nursing education}

Most contributions were made in nursing education, (36) $48.00 \%$ graduates indicated that they contributed by planning in-service education programmes for nursing personnel in order to update their knowledge and skills. According to Muller (2002: 491) in-service education lead to higher productivity in all nursing personnel irrespective of the category. Six $20.68 \%$ supervisors agreed that nursing graduates contributed mostly in capacity building of personnel through these in-service education programmes. Over and above $6.70 \%$ graduates contributed in the curriculum development of bridging course students that was introduced for the first time in their institutions.

\section{Contributions made in primary health care /clinics}

Contributions in primary health care/clinics were mainly made in the introduction of health education programmes for patients by (4) $5.30 \%$ graduates. Four $13.70 \%$ supervisors on the other hand mentioned that nursing graduates contributed by commencing HIV / AIDS counselling for patients and commencement of primary health care in the outpatients department and the clinics. Henry, Hamran and Sorenson (1995: 11) commented on the changes in the health systems which will affect the roles of nurse managers which they see as a shift in resources to primary health care.

\section{Developmental needs}

The graduates were asked to identify some developmental needs that will improve their skills in order to cater for the changing educational and health needs of the country. The graduates identified the following needs:

- Twelve $16,00 \%$ indicated the need for skills in transformational admiadministration management, including dealing with grievances from the public.

Matsane (1998: 60)her study on industrial relations in health care in the eighties and early nineties, observed that approaches to management used by nurse managers prior to the new era (27 April 1994) were rigid and that all means should be made to help nurse managers to acquire new skills of management that will be more flexible.

- Six $8.00 \%$ indicated the need for more development in business management in order to perfect their skills in budgeting, health service management and district health systems management skills. The above skills are required to improve their compe tencies in the management of health services, educational institutions and primary health care services.

The majority (43) $57.30 \%$ graduates needed development in clinical studies like clinical masters including intensive care and trauma care nursing courses. All the graduates expressed a need for computer literacy courses since the health services are changing to be in line with technological advances. There was also a need to produce graduates at doctoral levels in order to enhance the standard of nursing. The inclusion of the above aspects in the post-basic nursing programmes can improve graduates, marketability, relevance and competencies in catering for their educational needs and the health needs of the country.

\section{Suggestions made by supervisors for future preparation of the graduates}

The 29 supervisors of the graduates were asked to give suggestions as to which areas would be necessary for the post-basic programmes in order to cater for the needs of the country and those of the students. The suggestions were based on the three main areas of the post-basic programmes, that is nursing education, nursing management and primary health or community health nursing. These suggestions made by the supervisors will improve the future post-basic programmes of the University of Zululand.

\section{Suggestions on nursing management}

Most of the supervisors (15) $51.70 \%$ suggested courses focusing on assertiveness in order to improve communication skills, course on new legislation in order to improve patient care, transcultural nursing for provision of holistic nursing care, financial management so as to help in economising/ and proper utilization of material and human resources, transformational skill and human resource management. These suggestions made by the supervisors will improve the future post-basic programmes of the University of Zululand.

\section{Suggestions on nursing education}

The (9) $31.00 \%$ supervisors suggested that post-basic nursing education programmes should be focused on creative thinking in order to improve graduates problem solving skills, counselling skills and stress management skills that will both improve their interpersonal skills.

\section{Community health and Primary health care suggestions}

(5) $17.30 \%$ supervisors made suggestions on community health and primary health care areas like training nursing graduates in rural health and project management courses, in order to assist primary health care nurses in community project management.

\section{Conclusion}

From the above findings it can be concluded that the postbasic nursing programmes of the University of Zululand catered for educational needs of the students in Kwazulu- 
Natal Province. Also that programmes did not only cater for work needs of the nursing graduate, but also helped them to cope with the recent advances in health care and nursing education.

\section{Recommendations}

The following recommendations were made in order that the post-basic nursing programmes may be more relevant and appropriate to educational needs of the graduates:

An evaluation model should be formulated to continually evaluate programmes that are offered by each educational institution for effectiveness and relevance.

The Nursing Science Department of the University of Zululand should develop more advanced clinical programmes in midwifery, general nursing science, intensive care, trauma nursing care and a diploma in psychiatric nursing for graduates in order that they are more relevant and appropriate to the educational needs of the graduates.

The Nursing Science Department should also introduce primary health care programmes at certificate, diploma, baccalaureate and post graduate levels. These programmes may be offered as distance learning for greater accessibility.

Introduction of a certificate course on HIV/AIDS focusing on counselling, home based care and rights of people living with AIDS, and their carers, including nurses.

\section{Limitation of the study}

The researcher had difficulty in finding recent literature on the subject since there is not much research that was done on the subject.

\section{Summary}

This study confirmed that the past Post-basic programmes of the University of Zululand catered for the educational needs of the graduates. This is evidenced by many contributions that they made in the health services and educational institutions where they were working. But at the same time the majority of the graduates (43) $57.30 \%$ identified some future developmental needs in clinical masters for different specialisations. The supervisors made suggestions about future preparation of the graduates that should be focused on assertiveness, transcultural nursing, creativity and critical thinking to improve their communication skills and problem solving skills.

\section{Bibliography}

BILLING, DM \& HAISTEAD, TA 1998: Teaching in nursing: a guide for faculty. USA: WB Company.

BITZER, EM 1997: Programme evaluation in problem-based and community-based nursing education. Curationis. 20(1): $8-10$.
IEPARTMENT OF EDUCATION 1997: Outcome-Based education (OBE): Pretoria.

FERGUSON, LM \& CALDER, BL 1993: A comparison of preceptor and educator valuing of nursing student clinical performance: Journal of Nursing Education. 32 (10) 30 - 36 .

GUMBI, RV 1996: Human Resources development with primary health care ideology. Pretoria: Department of Health

HENRY, B, HAMRAN, G \& SORENSON, M 1995: Nursing Management in the Nordic countries: A health system perspective. International Review. 41 (1).

HUBER, D 1996: Leadership and Nursing Care Management. Philadelphia: WB Saunders \& Company

MATSANE, TE 1998: An investigation into the industrial relations system used in health care services with special emphasis on KwaZulu-Natal. Masters dissertation (Unpublished). Department of Nursing Science: University of Zululand.

MELLISH, JM \& BRINK, H 2001: Teaching the principles of Nursing. Durban: Butterworth.

MULLER, M 2002: Nursing Dynamics. Johannesburg: Heineman.

NZIMANDE, PN 1984: The role and functions of the nurse administrators in the comprehensive health care services in KwaZulu. D.Litt et Phil thesis (Unpublished) Pretoria: UNISA.

NZIMANDE, PN 1990: A manual of course programmes offered with the post-basic section. Nursing Department: University of Zululand.

PIETZAK, J RAMLAR, M, FORD, C, RENNER, L \& GUILBERT, N. 1990: Practical programme evaluation examples from child abuse prevention. USA: Sage Publications Ltd.

ROSSIE, PH \& FREEMAN, HE 1991: Evaluation : a systematic approach. $4^{\text {th }}$ Edition. London: Sage Publications Ltd.

ZUMA, N 1996: Final Draft National Human Resources development policy for South Africa. Directorate: Human Resources development. Pretoria: Department of Health. 